\title{
Isolation and connectedness among Black and Latinx physics graduate students
}

\author{
Rachel E. Scherr® \\ University of Washington, Bothell, Washington 98011, USA \\ Mike A. Lopez \\ The Ohio State University, Columbus, Ohio 43210, USA \\ Marialis Rosario-Franco \\ University of Texas at Arlington, Arlington, Texas 76019, USA
}

(Received 15 January 2020; accepted 1 October 2020; published 3 November 2020)

\begin{abstract}
Racial or ethnic isolation may negatively impact physics graduate students' academic and professional experience. An interview study with 16 doctoral students who were considered to be particularly at risk of such isolation found that (i) the students interviewed are mostly not the only member of their racial or ethnic group in their programs; (ii) students have diverse perceptions of who they consider to be part of their racial or ethnic group, such that their unique perspectives need to be taken into account by programs that wish to support them; and (iii) students report negative racial experiences in their programs, such as bias, expectations of service, family and financial difficulties, and political threats. Overall, these findings present both challenges and opportunities for supporting Black and Latinx physics graduate students in ways that are meaningful to them.
\end{abstract}

DOI: 10.1103/PhysRevPhysEducRes.16.020132

\section{INTRODUCTION}

In the United States, from 2013 to 2017, less than 6\% of doctoral degrees in physics were awarded to Latinx ${ }^{1}$ students, less than $3 \%$ to Black students, and less than $1 \%$ to Indigenous students-much lower than the representation of these groups in the U.S. population [2]. The American Physical Society (APS) seeks to improve access to graduate education through the APS Bridge Program, which creates sustainable transition (bridge) programs and a national network of doctoral granting institutions that provide substantial mentoring for students to successfully complete Ph.D. programs [3]. In supporting BIPOC ${ }^{2}$ students to obtain doctoral degrees in physics, the APS Bridge Program of necessity supports students to participate in graduate programs that may not include other members of the student's racial or ethnic group - not

Published by the American Physical Society under the terms of the Creative Commons Attribution 4.0 International license. Further distribution of this work must maintain attribution to the author(s) and the published article's title, journal citation, and DOI.

${ }^{1}$ The term Latinx describes the U.S. population of people tracing their roots to Latin America and Spain, and is a genderneutral alternative to Latino or Latina. For discussion of the development of this and other pan-ethnic labels, see Ref. [1].

${ }^{2}$ The term BIPOC stands for "Black, Indigenous, People Of Color." It is meant to unite people of color in the work for liberation while intentionally acknowledging that not all people of color face the same levels of injustice. because anyone wants them to be isolated, but because a given graduate program may have no other students from that racial or ethnic group before the APS Bridge student arrives. Racial or ethnic isolation may negatively impact students' academic and professional experience [4,5].

An interview study was conducted with APS Bridge students who were considered to be particularly at risk of such isolation. The purpose of the study was to learn whether students are experiencing racial or ethnic isolation and to learn from their experiences, including what departmental structures and faculty behaviors students experience as supportive, in order for programs to better support BIPOC students. Findings of this study include that (i) the APS Bridge students interviewed are mostly not the only member of their racial or ethnic group in their programs; (ii) students have diverse perceptions of who they consider to be part of their racial or ethnic group, such that their unique perspectives need to be taken into account by programs that wish to support them; and (iii) students report negative racial experiences in their programs, such as bias, expectations of service, family and financial difficulties, and political threats. Overall, these findings present both challenges and opportunities for supporting BIPOC physics graduate students in ways that are meaningful to them.

\section{PREVIOUS RESEARCH}

Isolation and connectedness in school are known to be connected to students' coping skills, motivation, school 
participation, and grit [6-10]. Important factors in a sense of belonging include

"students' perceived social support on campus, a feeling or sensation of connectedness, the experiences of mattering or feeling cared about, accepted, respected, valued by, and important to the group (e.g., campus community) or others on campus (e.g., faculty, peers)" [11].

Our findings about isolation and connectedness among BIPOC physics graduate students are motivated by three different theoretical perspectives, which identify distinct causes for underrepresentation: (i) Critical theories (especially critical race theories) identify racism as the reason for persistent educational inequality; (ii) social psychology identifies interpersonal behaviors that exacerbate underrepresentation; and (iii) research on workplace policies attributes underrepresentation to institutional structures and practices. All of these are relevant to the experiences reported by students in this study.

Critical race perspectives are diverse but share at least two common interests: (i) to "understand how a regime of white supremacy and its subordination of people of color have been created and maintained in America" and (ii) to not only "understand the vexed bond between law and racial power but to change it" [12]. Critical race theorists in education have problematized the notions of meritocracy that imbue educational systems and identify racism as the reason for persistent educational inequality [13]. Critical race theory is synergistic with critical theories broadly construed, which attribute inequity to the structures that maintain and reproduce power, and imagine transformative possibilities for more equitable futures that begin with the development of critical consciousness $[14,15]$. Critical race theory informs this study in that the study interprets student experiences in terms of racialized power structures that operate in U.S. institutions of higher education and in U.S. society as a whole.

Findings in social psychology call attention to exclusionary interpersonal attitudes and structures. Microaggressions [16,17], implicit or explicit bias [18,19], and overt sexual harassment [20] are especially prominent in environments in which there is extreme underrepresentation. Studies of professional physicists document how a strong "brilliance requirement" in physics works to exclude women and certain racial and ethnic groups from physics graduate education [21-26]. In a classic study, Seymour observes that "entry to freshman science, mathematics or engineering suddenly makes explicit, and then heightens, what is actually a long-standing divergence in the socialization experiences of young men and women ${ }^{3} \ldots$ of all

\footnotetext{
${ }^{3}$ We prefer a more gender-inclusive statement of this finding: that entry to freshman STEM courses makes explicit the longstanding divergence in the socialization experience of people with different gender identities.
}

ethnicities [who] are entering an educational system which has evolved to support the ongoing socialization of only one group-namely, white males" [27]. Students in our study report experiencing implicit bias, microaggressions, and stereotype threat, as is typical for people of color in the U.S. [17,28,29].

Finally, research focused on workplace policies and structures shows how institutional practices exacerbate underrepresentation in all areas, including physics. At the level of departmental policy, a review of forty years of scholarship on the postsecondary educational experiences of women of color in science, technology, engineering, and mathematics (STEM) presents a complex portrait of the myriad factors that influence their undergraduate and graduate experiences, including funding issues, mentorship and role models, and the STEM climate [30]. Other researchers point to inadequate parental leave policies for employees and gender differences in work-family balance and labor [31,32]. For example, departments may not have a family leave policy or family health insurance for graduate students, support a student club for women or BIPOC in physics, or provide staff support for outreach to underrepresented groups.

\section{DATA COLLECTION AND ANALYSIS}

\section{A. Design framework}

A guiding methodological framework for this study is provided by feminist standpoint theory, which asserts that the study of people in marginalized groups needs to begin with their own lives as they experience them [33-36]. This starting point for research "will generate less partial and distorted accounts" [37] than those that favor the perspectives of dominant groups, because dominant groups' accounts are biased by the need to separate and insulate themselves from the suffering that their dominance causes [34,36]. Marginalized groups' "concrete experience" provides the ultimate "criterion for credibility" [35], and taking their perspective as a starting point can begin to "repair the historical trend of women's [and other groups'] misrepresentation and exclusion from the dominant knowledge canons" [34]. Standpoint theory guides the basic design of this research as an interview study, centering the voices of student participants in the APS Bridge program. Standpoint theory also informs the authorship of this paper: two of the authors are APS Bridge students (Lopez and Rosario-Franco).

\section{B. Participants}

Interviews for this study were conducted in January and February of 2019 by remote videoconference and recorded. Participants in this study met the following criteria:

- They were APS Bridge Fellows (students who received stipends from APS to participate in physics graduate programs). 
TABLE I. Percentage of physics degrees granted to BIPOC students at the participating institutions in this study.

\begin{tabular}{lcc}
\hline \hline University & M.S. & Ph.D. \\
\hline A & $0.0 \%$ & $0.0 \%$ \\
B & $8.0 \%$ & $14.3 \%$ \\
C & $6.8 \%$ & $10.0 \%$ \\
D & $50 \%$ & $18.2 \%$ \\
E & $0.0 \%$ & N/A \\
F & $8.3 \%$ & $1.9 \%$ \\
G & $6.8 \%$ & $10 \%$ \\
H & $12.5 \%$ & $0.0 \%$ \\
I & $0.0 \%$ & $2.7 \%$ \\
J & $4.8 \%$ & $0.0 \%$ \\
K & $28.6 \%$ & $44.4 \%$ \\
L & $5.6 \%$ & $0.0 \%$ \\
M & $6.3 \%$ & $3.5 \%$ \\
\hline \hline
\end{tabular}

- They were members of a racial or ethnic group defined as underrepresented by the American Physical Society: Black, Latinx, or Indigenous.

- When they were in their first year of their physics graduate program (which was not the year they were interviewed), they were the only APS Bridge Fellow that enrolled in that program.

- They were not attending a historically Black college or university.

- They were not part of another large program supporting BIPOC in physics graduate programs (e.g., another Bridge program)

These criteria were intended to select for students who were particularly at risk for racial or ethnic isolation. At the time of the study there were 26 such participants; 16 were interviewed for this study (61\% response rate). Of these participants, 12 identified as male and four as female. Eleven identified as Hispanic or Latino/Latina/Latinx, and five identified as Black or African American. There were no Indigenous participants in this study. Five were in master's programs and 11 were in doctoral programs. Quotations from students below are identified with a pseudonym, the student's preferred term describing their race or ethnicity, and (if this information was available) the number of years the student had been engaged in physics graduate education.

The universities that these students attended (designated A-M) were all in the United States and included institutions in the East, West, Midwest, and South. There were no more than two students from any single graduate program. To help convey the environment for BIPOC students in each of these physics graduate programs, Table I shows the percentage of physics masters' and doctoral degrees awarded to U.S. citizens and permanent residents that are granted to Black, Latinx, and Indigenous students at each program (data aggregated from 2015 to 2017 [38]). These data demonstrate that all students in this study attended physics graduate programs where BIPOC students are in the minority, and most attended physics graduate programs whose representation of BIPOC is below the national average for physics graduate programs (11\% for master's degrees, $7 \%$ for doctoral degrees).

\section{Positionality}

The interviewers for this study were both senior academic professionals in physics who identify as white women (Scherr and Robertson). Social and political context influence any interview; whether participants and interviewers have similar or different social identities, their positionality influences both what interviewees say and what interviewers (and researchers) perceive [39]. In this study, senior white women associated with a major professional society interviewed junior people of color about their racial or ethnic experiences in a typically stressful professional setting (physics graduate education). To help create an environment with the best opportunity for shared understanding, interviewers took the following steps:

- Interviewers explicitly invited interviewees to decline any question that they preferred not to answer.

- Interviewers first asked interviewees questions about their experience in their graduate program, without reference to race or ethnicity: how their classes and research were going, what their relationships with faculty were like, and so on. The intention was to allow students to speak about their experiences from whatever perspective felt primary to them, without priming them.

- Later in the interview, interviewers explained the reasons for asking questions about interviewees' racial or ethnic experiences, and asked for their consent to share experiences from their perspective as a member of an underrepresented group. The intention was to invite and endorse students' speaking from their perspective as a member of an underrepresented group.

- Interviewers invited interviewees to describe their racial or ethnic identity in their own terms and used interviewees' preferred descriptors, rather than imposing categories defined by the American Physical Society or other entities.

After the interviews were completed, two APS Bridge students who had been interviewed (Lopez and RosarioFranco) contributed to identifying themes in the data and provided key interpretations of student experiences. After the manuscript was drafted, all interview participants whose quotations appear below were given the opportunity to read it and affirm or correct interpretations of their statements. This member checking is in line with feminist standpoint epistemology in the sense that participants are the ultimate judges of whether researchers' interpretations are consistent with their experience.

\section{Interview protocol}

The interview protocol is reproduced below. The interviews were semistructured; the protocol provided guidance for the interview, but the questions were not always asked 
precisely in these words or in this order. For example, if interviewees identified their race or ethnicity in response to question 2, interviewers did not ask for it again in question 3.

My name is [name], and I'm physics faculty at [institution]. I work with the APS Bridge program to help them do research to improve the program. We are interviewing you because you were recruited into grad school partly through the APS Bridge program, and we want to find out how well that program is reaching its goal: to increase the number of physics Ph.D.s from underrepresented groups. If there are any questions we ask that you prefer not to answer, feel free to decline.

1. How is school going for you?

- How are your classes?

- How is your research?

- Do you do homework with other students or by yourself?

- Who do you have a relationship with on the faculty? What is that like?

2. How is the bigger picture of your life, such as your living situation and any obligations outside of school?

The goal of the APS Bridge program, as you may know, is to increase the number of physics Ph.D.s from underrepresented groups. The APS knows already how many students from underrepresented groups are being admitted to programs and whether they are still in graduate school, but they know less about the experience students from underrepresented groups are having while they are in graduate school. We'd like to know more about the experiences of graduate students from underrepresented groups in physics, so that the APS Bridge program can better support people in the future.

3. Do you identify as a member of an underrepresented group in physics? How would you describe yourself? [Answer = descriptor, below]

- (If yes:) Would you be willing to share your experiences from your perspective as [descriptor] to help us answer this question?

- (If yes:) Do you think that being [descriptor] matters for your experience in this program? If so, how?

- Are there any other [descriptor] students in your physics graduate program (that you know of)?

4. If there were a prospective graduate student considering your program, would you recommend your program to them? Why or why not? Would it matter if the student was [descriptor]?

5. Is there anything else you would you want to tell the APS Bridge program about how things are going for you?

\section{E. Analysis}

Interviews were transcribed for analysis. Each transcript was systematically examined from beginning to end for (i) whether the student described experiencing racial or ethnic isolation, (ii) difficulties the student described that they attributed to their racial or ethnic identity, and (iii) the student's description of faculty behaviors or departmental structures that they experienced as supportive. Interviews were coded with these three codes, each of which could potentially appear multiple times in each interview. For each code that was assigned, a student quotation was identified that illustrated the code. All quotations illustrating a specific code were grouped and examined collaboratively by all three authors for emergent themes. For example, among the quotations in which students described whether they experienced racial or ethnic isolation, two themes emerged: first, APS Bridge students are mostly not the only member of their racial or ethnic group in their program, and second, APS Bridge students have diverse perceptions of who is in their identity group.

Data associated with the first two codes (experiences of racial or ethnic isolation and difficulties attributed to racial or ethnic identity) comprise Sec. IV. Data associated with the third code (supportive faculty behaviors and departmental structures) comprise Sec. VI. Multiple quotations are included for each section, thereby illustrating the connection between each quotation and that theme. Not every coded quotation is reported in this manuscript: the three authors collaboratively selected those quotations that illustrated the themes most eloquently and completely. Finally, the three authors collaborated to interpret the quotations in terms of the theoretical frameworks described above: critical race theory, social psychology findings, and research on workplace structures.

\section{FINDINGS}

\section{A. APS Bridge students are mostly not the only member of their racial or ethnic group in their program}

One measure of isolation and connectedness for our study is whether students have other students in their program who they consider to be like them $[4,5]$. Twelve out of the 16 students in the study (75\%) reported being aware of other students in their graduate program who they considered to be members of their racial or ethnic group. In several cases, students described a meaningful connection to those other students. This is a significant finding: even though these students were, in their first year of their physics graduate program, the only APS Bridge Fellow that enrolled in that program, they mostly did not experience extreme racial or ethnic isolation.

[At the first program I attended], the department was remarkably diverse and because they're also in Florida, there was a huge, pretty large Hispanic, Latino and Puerto Rican specific community, even within the department. As such, I felt very quickly a part of some community as a subset of the physics department. And it 
was really nice, really encouraging, very welcoming in that regard.-Bobby (Latino, 6th year)

In our department at the graduate level, there's one. $H e$ 's older and I get along with him very well. I've met his wife and I find a sense of community with him. ...If someone's looking for a Hispanic centered department, this isn't it. And that doesn't particularly bother me, but I know that even having one Hispanic person there is nice for me.-Elena (Hispanic, lst year)

A minority of students $(25 \%)$ described being the only member of their racial or ethnic group enrolled in their program. Others reported that whether or not they were the only member of their racial or ethnic group in their program, they felt socially isolated:

There's really-there's no one here. There are no other students of color... I think it's a difficult place to live... There's literally like one Black grad student per program at this university.-Renee (Black, 3rd year)

The absence of [community] in my [current] program has definitely had implications on my mental health and my ability to be productive in my research. As far as normal everyday activities, because there is such a lack of diversity in the department, there aren't a whole lot of opportunities for me to express that part of my culture.Bobby (Latino, 6th year)

You don't realize that you're really missing other Hispanic people in your program until you finally see another Hispanic person, you know? When you see another person, like you're delighted, "oh there's another person like me, nice." At the same time you're like, why isn't there more?-Joaquin (Hispanic, 2nd year)

Multiple students described the pattern of low enrollment for BIPOC as adding hardship to their graduate school experience. These students do not have access to the experience of connectedness that contributes to student success [11].

\section{B. APS Bridge students have diverse perceptions of who is in their racial or ethnic group}

Whether a student feels racially or ethnically isolated in their graduate program depends on what they understand their racial or ethnic group to be. For example, one student described that although there are other Black people in her program, they are from Africa, and therefore do not share her cultural experiences.

It's like one Black person every two years. And actually I was the only Black American one. The others were all from Africa. The guy that came before me is African, and the guy that's coming after him is also African. Even the undergraduate Black students, they're all African. So that's just a completely different cultural setting.Renee (Black, 3rd year)

Other students also perceived significant difference in cultural experiences between students who grew up in the mainland United States and students who were raised elsewhere:

I have dual citizenship, but I grew up in the United States, so I mostly identify as American. The other Latino student in our class, it was another student who grew up in Florida, his parents immigrated from Puerto Rico. That's called the second generation, that's like what I am. And then there was someone else who came directly from Peru and went to undergrad in United States. So they are sort of assimilated but, but definitely their experience is a lot different from the second generation experience.-Cody (Latino, 4th year)

I know that there are people [in my program] with Latino names. There's one guy from Puerto Rico, but other than him... it's people who have parents who are Latino, but they themselves grew up in the US. That's quite different. The only actual Latino that I've met is [name of friend].-Javier (Latino, 4th year)

In some cases, students' descriptions represent political and cultural misconceptions. For example, the term "immigrated" does not correctly describe relocation from Puerto Rico, since Puerto Rico is in the United States; using terms such as "first-generation" to describe Puerto Rican people who move to the U.S. mainland might imply that they were not U.S. citizens before moving, when in fact Puerto Ricans were granted U.S. citizenship in 1917; and limiting the term "Latino" to second-generation immigrants is not typical [1]. Such nonstandard use of political terminology highlights the need to learn what terms people use to describe themselves and others, and what those terms mean to them. For example, the students above may have intended to acknowledge the distinctive experiences of students raised outside the U.S. mainland.

\section{APS Bridge students report negative racial experiences in their programs}

Multiple students, when asked if their racial or ethnic identity had mattered for their graduate program experience, stated that they had experienced little or no explicit racial prejudice or antagonism directed against them.

Fortunately for me, it's not been an issue. I mean, I do notice that I'm one of the few Hispanic people in the program. But I've never had that negatively impact me.-Alfredo (Hispanic, 5th year) 
[Being half Mexican] makes me aware of certain things that I feel like I wouldn't be otherwise, but I don't think that it matters to the professors... I was very worried about being Mexican in [southern state] when I first moved here. And I don't think it has been an issue the whole time, which is good.-Daniel (Hispanic)

Luckily nobody's really discriminated about that in the department, so that's good. I hope not. I didn't feel anything like that.-Joaquin (Hispanic, 2nd year)

However, multiple students still describe negative racial experiences, such as implicit bias [40,41]:

It didn't matter whether I was top three in the class or towards the middle, the attitude was always, you're struggling. ...I actually didn't recognize it until another student on my experiment, an Indian American girl, specifically asked me this question: "Have you ever gotten the feeling that they were professors that no matter how well you did, they just always thought that you were having a hard time?" And immediately I was like, "Yeah, actually."-Renee (Black, 3rd year)

Such "racism without racists" has been described as typifying current racial experiences in the United States [42]. Another typical current experience for people of color is "brief and commonplace daily verbal, behavioral, and environmental indignities, whether intentional or unintentional," that negatively single out people of color ("microaggressions") [17,28,29]. One student described others as repeatedly drawing unnecessary attention to his status as a person of color:

You don't really realize you're a person of color until you go to college... It was like, oh, you're a person of color, here are all these programs could apply to. And I'm like, Whoa, okay. Yeah. It's fine. I just never thought about it. You just realize that people are just going to point that out, you know, regardless of whether you want to think about it. So I just kind of don't think about it anymore. It's a thing that's part of my life and that will probably carry on, for jobs or whatever. People are going to be like, you're a person of color. I'm like, great. I know that. Thank you.-Cesar (Latinx, 2nd year)

Microaggressions have cumulative negative effects, impacting both academic performance and health outcomes [43-45]. Another student described coping with pervasive stereotype threat [40], which negatively impacted his academic performance; learning about stereotype threat, meanwhile, supported his persistence in his program.

I personally never faced any kind of racial issues on campus, but I always felt stereotype threat when I was in classes and I wasn't doing well. I was afraid that students would think I'm not doing well because I'm African American and not just because I just don't understand what's happening. ...There were several instances where students would ask other students to study, like they would ask my neighbor and the person over here, but they wouldn't ask me. I was like, are they not asking me because they think I know it, or are they not asking me because I'm Black? My entire time, there was lots of stress and lots of stereotype threat and always being worried about what people think of me while I'm here. When I finally figured out [that it was stereotype threat] that was bothering me, I just told myself that I wasn't going to let that be something that I'm concerned with anymore and just accept it. It is what it is. I want to get a PhD in physics and I want to study physics full time forever and ever. Amen.-Shawn (African American, 3rd year)

A different student described a related pressure that she feels to represent her various identities favorably in her department-pressure that leads her to take on additional service responsibilities, as is common for women and people of color in academia [46-48]:

When you're part of an underrepresented group, you feel like you're just so lucky to be there because there aren't many like you. You can't possibly say no to service. You need to be there. You need to be that person for the department. You're representing women, you're representing Latinas... there's no other [person from your group] in your department. You can't say no to this, you can't say no to that. No one is necessarily putting that pressure on you, but you still feel it. I think that's something that not everyone experiences.Miranda (Latina, 4th year)

Multiple students described extra hardships associated with socioeconomic class, including both financial instability and family history that does not include higher education.

Where it's different is the resources that allow people to go to graduate school. For me it was a hard job even just financially because knowing that I could have gone and gotten a master's or an engineering degree or whatever and I could be making a lot more money and my family doesn't have very much money to begin with. That's a hard thing for me to conceptualize as being first generation. That I could be providing more for my whole family overall, or I could just be making more money, which is something that I've struggled with my whole life.-Cesar (Latinx, 2nd year)

My mom came from a rural town in the interior of [country]. She didn't go to college. When she came to the United States, she was working as a cleaning lady and then a seamstress. She had low wage jobs my whole 
life. That's who she is and what opportunities she had. It definitely impacts who I am, what I expect of myself, the pressures that I feel and what's realistic for me to attain. ...More like a socio-economic sense, which is definitely linked with like national identity and heritage.-Cody (Latino, 4th year)

None of my parents ever went to school. My background was not very intellectual. My desire to pursue physics is completely self-driven. I don't have that familial support system to draw from or advise from, to give me some kind of role model or example.-Malik (Black, 2nd year)

The biggest setback in terms of under-represented groups goes back to your upbringing. My family doesn't even know what physics is or what it does. Their highest education, my mom has some college, my dad is like, you know, I don't even know what my dad went through.Robert (Black)

These hardships reflect the social structures that have tended to subordinate people of color in the U.S., and therefore embody the concerns of critical race theory. In certain cases, students experienced the "vexed bond between law and racial power" [12] even more directly, in the form of political demonstrations that threatened their safety.

I didn't think about being African American until we started having some issues with a confederate monument that was on our campus. It wasn't until that time that I started to actually feel threatened on campus. I didn't feel as safe here anymore. I was joking to my classmates, "How fast can I get my Ph.D. and get out of here and never come back ever again?" You know? And part of me was serious._-Shawn (African American, 3rd year)

\section{LIMITATIONS}

This study is based on 16 students. This represents a response rate of $60 \%$ among those that were recruited, but the group of BIPOC physics graduate students is larger than the recruitment pool. Four of the study participants are women, which is approximately representative of the national percentage of women in physics.

This study relies on participants' reports of their own experiences. This is appropriate for the claims being made and reflects people's right to define their own experience. At the same time, any self-report is limited by the extent of participants' self-awareness, especially given the possibility of (intentionally or unconsciously) suppressing unpleasant racial experiences. In addition, the positionality of the interviewers influences both what interviewees say and what interviewers perceive. The author(s) take the position that the best mutual understanding comes from trusting relationships in which the power dynamic is reduced to the extent possible through a variety of means: e.g., confidentiality, open-ended interview questions, and interviewers who are independent of the agency funding the program.

\section{RECOMMENDATIONS FOR PHYSICS GRADUATE PROGRAMS}

One aim of this research is to help departments engage appropriately with the question of how best to support APS Bridge students, or other BIPOC students, given the complexity of how their racialized experience matters to their education. This study supports the following recommendations.

\section{A. Foster a racially, ethnically, and culturally diverse environment}

Multiple students in this study expressed that a racially, ethnically, and culturally diverse environment contributed to a positive experience in their graduate program:

There are a lot of people from different places and I fit myself into a different place. People from Europe, from Canada, and from Asian countries, and they all have different perspectives. And I bring another different perspective.-Alfredo (Hispanic, 5th year)

We have a lot of people from overseas, and our group, we have functions where you share your culture for example, like food or something like that. So it makes you feel really, really welcome. Like it doesn't make you feel like an outsider. Most of our students are from China and Japan and India and Kazakhstan. We're very, very diverse. I feel really, really good; I feel like I am at the right place.-Krystal (African American)

That was another thing that helped me quite a lot: getting involved in an experiment where I got to see other students of color from around the world. None of them were Black, but there were some Asian American students that I got to talk to who had somewhat similar experiences to what I had.-Renee (Black, 3rd year)

These students expressed feeling supported by the community they formed with foreign students from Europe, Canada, and Asia, or with Asian American students. These students may belong to groups that constitute minority groups in the U.S. as a whole, but not in physics. Graduate programs should not conflate these groups with groups that are underrepresented in physics, i.e., Black, Latinx, and Indigenous (according to the IPEDS completion Census taken from 2013-2017 [2]). The needs and experiences of these groups are different (as described below), and the community they provide is distinct from the 
community potentially provided by students in underrepresented groups.

\section{B. Take supportive political positions and invite students to teach faculty how politics permeates academic life}

Students who are exposed to political demonstrations that threaten people of color describe that supportive action from their graduate program makes a difference to their persistence:

What really helped me move on from it was that the physics department, they were like, "This is unacceptable. We want you to feel safe and we do not condone any of this and we want the monument down as much as you do." With that, I felt that I was supported in my department. Even if I didn't feel supported in the university as a whole, I felt safe in my working environment.-Shawn (African American, 3rd year)

Such support potentially contributes to the transformation called for by critical theorists [14,15], as well as embodying supportive workplace policies [30]. Another student, in contrast, described being left to wonder whether her graduate program cared about her safety:

Watching the news [of police killings of unarmed Black people] became a very difficult thing for me because I would see these things happening and it really felt like no one else cared. Ifelt like the attitude was, well, "Why are you focusing on that? You should be doing your work," as if it shouldn't affect you or it didn't really matter. It really got to the point where I felt like if that were me, what were their response be? If I am walking home at 2:00 AM when I was working on my thesis, and somebody perceives me as a threat and something happens to me, what would the department's response be?-Renee (Black, 3rd year)

Graduate programs should be explicit about taking political positions to protect their students' well being, including physical safety, mental health, and social inclusion. In addition, graduate programs should recognize that BIPOC students are a resource for helping physics faculty (who are mostly members of dominant groups) identify the ways in which politics permeates academic life.

\section{Invest resources to support student initiatives}

As part of this research investigation, BIPOC students shared how they themselves create structures in their physics programs to better meet their own expectations. For example, students in this study described starting or leading physics graduate student associations to better support new students; advocating for the formation of departmental committees on diversity and inclusion; and initiating an outreach program to link students from their demographic group to Ph.D. opportunities in physics. Graduate programs should not only allow this to happen, but also invest resources to sustain such structures, such as staff support for the physics graduate association or a salaried position for a diversity officer. Such investment ultimately benefits graduate education for all students.

\section{Serve different underrepresented groups according to their specific needs and interests}

Students from different underrepresented groups are marginalized differently in physics programs. For example, immigrants who move from their home countries to pursue higher education in the U.S. will have different experiences than Mexican Americans, African Americans, or Puerto Ricans raised on the mainland; students who are the first generation in their family to attend college may experience disorienting shifts in environment, culture, and class; and students with intersecting marginalized identities may experience a combination of those experiences with compounding effect $[49,50]$. Predominantly white physics graduate programs that want to be more inclusive (perhaps by accepting APS Bridge students) should proactively consider how to engage, learn from, accept, and meet the expectations of BIPOC students, in communal decisionmaking processes that involve those students.

\section{ACKNOWLEDGMENTS}

The authors gratefully acknowledge the APS Bridge student participants for their time and candor in interviews, Theodore Hodapp for conceiving and supporting the study, and Amy Robertson for conducting interviews and contributing to the theoretical framework. This material is based upon work supported by National Science Foundation Grants No. 1611318 and No. 1143070.
[1] G. C. Mora, Making Hispanics: How Activists, Bureaucrats, and Media Constructed a New American (University of Chicago Press, Chicago, London, 2014).
[2] The Integrated Postsecondary Education Data System, https://nces.ed.gov/ipeds/use-the-data (accessed Jun. 06, 2019). 
[3] T. Hodapp and E. Brown, Making physics more inclusive, Nature (London) 557, 629 (2018).

[4] D. Wilson, D. Jones, F. Bocell, J. Crawford, M. Joo Kim, N. Veilleux, T. Floyd-Smith, R. Bates, and M. Plett, Belonging and academic engagement among undergraduate STEM students: A multi-institutional study, Res. High. Educ. 56, 750 (2015).

[5] V. Tinto, Completing College: Rethinking Institutional Action, 1st ed. (University of Chicago Press, Chicago, 2012).

[6] S. Vaz et al., The personal and contextual contributors to school belongingness among primary school students, PLoS One 10, e0123353 (2015).

[7] R. F. Baumeister and M. R. Leary, The need to belong: desire for interpersonal attachments as a fundamental human motivation, Psychol. Bull. 117, 497 (1995).

[8] C. Goodenow, Classroom belonging among early adolescent students: Relationships to motivation and achievement, J. Early Adolesc. 13, 21 (1993).

[9] R.W. Larson, Toward a psychology of positive youth development, Am. Psychol. 55, 170 (2000).

[10] D. Verdín, A. Godwin, A. Kirn, L. Benson, and G. Potvin, Understanding how engineering identity and belongingness predict grit for first-generation college students, Sch. Eng. Educ. Grad. Stud. Ser. Apr. 2018, https://docs.lib .purdue.edu/enegs/75.

[11] T. L. Strayhorn, College Students' Sense of Belonging: A Key to Educational Success for All Students, 2nd ed. (Routledge, New York, 2019).

[12] Critical Race Theory: The Key Writings That Formed The Movement, edited by K. Crenshaw, N. Gotanda, G. Peller, and K. Thomas (The New Press, New York, 1996).

[13] G. Ladson-Billings and W. Tate, Toward a critical race theory of education, Teach. Coll. Rec. 97, 47 (1995), https://www.tcrecord.org/Content.asp?ContentId=1410.

[14] P. Freire and D. Macedo, Pedagogy of the Oppressed, 30th Anniversary ed. (Continuum, New York, 2000).

[15] H. Giroux, Ideology, Culture and the Process of Schooling (Temple University Press, Philadelphia, PA, 1984).

[16] R. S. Barthelemy, M. McCormick, and C. Henderson, Gender discrimination in physics and astronomy: Graduate student experiences of sexism and gender microaggressions, Phys. Rev. Phys. Educ. Res. 12, 020119 (2016).

[17] D. W. Sue, Microaggressions in Everyday Life: Race, Gender, and Sexual Orientation (John Wiley \& Sons, New York, 2010).

[18] A. A. Eaton, J. F. Saunders, R. K. Jacobson, and K. West, How gender and race stereotypes impact the advancement of scholars in STEM: Professors' biased evaluations of physics and biology post-doctoral candidates, Sex Roles 82, 127 (2020).

[19] C. A. Moss-Racusin, J. F. Dovidio, V. L. Brescoll, M. J. Graham, and J. Handelsman, Science faculty's subtle gender biases favor male students, Proc. Natl. Acad. Sci. U.S.A. 109, 16474 (2012).

[20] L. M. Aycock, Z. Hazari, E. Brewe, K. B. H. Clancy, T. Hodapp, and R. M. Goertzen, Sexual harassment reported by undergraduate female physicists, Phys. Rev. Phys. Educ. Res. 15, 010121 (2019).
[21] L. Bian, S.-J. Leslie, and A. Cimpian, Evidence of bias against girls and women in contexts that emphasize intellectual ability, Am. Psychol. 73, 1139 (2018).

[22] A. Cimpian and S.-J. Leslie, The brilliance trap, Sci. Am. 317, 60 (2017).

[23] S.-J. Leslie, A. Cimpian, M. Meyer, and E. Freeland, Expectations of brilliance underlie gender distributions across academic disciplines, Science 347, 262 (2015).

[24] J. R. Posselt, Inside Graduate Admissions: Merit, Diversity, and Faculty Gatekeeping, 1st ed. (Harvard University Press, Cambridge, MA, 2016).

[25] J. R. Posselt, Toward inclusive excellence in graduate education: Constructing merit and diversity in $\mathrm{PhD}$ admissions, Am. J. Educ. 120, 481 (2014).

[26] R. E. Scherr, M. Plisch, K. E. Gray, G. Potvin, and T. Hodapp, Fixed and growth mindsets in physics graduate admissions, Phys. Rev. Phys. Educ. Res. 13, 020133 (2017).

[27] E. Seymour, Talking About Leaving: Why Undergraduates Leave the Sciences, 1st ed. (Westview Press, Boulder, CO, 2000).

[28] R. A. Donovan, D. J. Galban, R. K. Grace, J. K. Bennett, and S.Z. Felicié, Impact of racial macro- and microaggressions in black women's lives: A preliminary analysis, J. Black Psychol. 39, 185 (2012).

[29] W. A. Smith, W. R. Allen, and L. L. Danley, 'Assume the Position ... You Fit the Description': psychosocial experiences and racial battle fatigue among African American male college students, Am. Behav. Sci. 51, 551 (2007).

[30] M. Ong, C. Wright, L. Espinosa, and G. Orfield, Inside the double bind: A synthesis of empirical research on undergraduate and graduate women of color in science, technology, engineering, and mathematics, Harv. Educ. Rev. 81, 172 (2011).

[31] A. Byars-Winston, B. Gutierrez, S. Topp, and M. Carnes, Integrating theory and practice to increase scientific workforce diversity: A framework for career development in graduate research training, CBE Life Sci. Educ. 10, 357 (2011).

[32] S. J. Ceci and W. M. Williams, Understanding current causes of women's underrepresentation in science, Proc. Natl. Acad. Sci. U.S.A. 108, 3157 (2011).

[33] S. G. Harding, Introduction; Standpoint theory as a site of political, philosophic, and scientific debate, in The Feminist Standpoint Theory Reader: Intellectual and Political Controversies, edited by S. G. Harding (Routledge, London, 2004), pp. 1-16.

[34] A. Brooks, Feminist standpoint epistemology: Building knowledge and empowerment through women's lived experience, in Feminist Research Practice: A Primer, edited by S. N. Hesse-Biber and P. L. Leavy (SAGE Publishing, Thousand Oaks, CA, 2007), pp. 53-82.

[35] P. H. Collins, Learning from the outsider within: The sociological significance of black feminist thought, Soc. Probl. 33, S14 (1986).

[36] A. M. Jaggar, Feminist politics and epistemology: The standpoint of women, in The Feminist Standpoint Theory Reader: Intellectual and Political Controversies, edited by S. G. Harding (Routledge, London, 2004), pp. 55-66. 
[37] S. Harding, Rethinking standpoint epistemology: What is 'strong objectivity'?, Centen. Rev. 36, 437 (1992), https:// www.jstor.org/stable/23739232.

[38] How Does Your Institution Compare? http://www.aps.org/ programs/education/statistics/compare.cfm (accessed Jun. 11, 2020).

[39] F. Sultana, Reflexivity, positionality and participatory ethics: Negotiating fieldwork dilemmas in international research, ACME: Int. J. Crit. Geographies 6, 374 (2007), https://acme-journal.org/index.php/acme/article/view/786.

[40] C. M. Steele and J. Aronson, Stereotype threat and the intellectual test performance of African Americans, J. Pers. Soc. Psychol. 69, 797 (1995).

[41] A. G. Greenwald, D. E. McGhee, and J. L. K. Schwartz, Measuring individual differences in implicit cognition: The implicit association test, J. Pers. Soc. Psychol. 74, 1464 (1998).

[42] E. Bonilla-Silva, Racism without Racists: Color-Blind Racism and the Persistence of Racial Inequality in the United States (Rowman \& Littlefield Publishers, Lanham, MD, 2006).

[43] D. H. Chae, K. D. Lincoln, and J. S. Jackson, Discrimination, attribution, and racial group identification: Implications for psychological distress among Black Americans in the national survey of american life (2001-2003), American Journal of Orthopsychiatry 81, 498 (2011).
[44] L. Ayalon and A. M. Gum, The relationships between major lifetime discrimination, everyday discrimination, and mental health in three racial and ethnic groups of older adults, Aging Mental Health 15, 587 (2011).

[45] D. Solorzano, M. Ceja, and T. Yosso, Critical race theory, racial microaggressions, and campus racial climate: The experiences of African American college students, J. Negro Educ. 69, 60 (2000), https://www.jstor.org/stable/2696265.

[46] The Costs for Minorities of Performing Service Work in Academe (opinion) Inside Higher Ed. https://www .insidehighered.com/advice/2018/02/02/costs-minoritiesperforming-service-work-academe-opinion (accessed Sep. 11, 2019).

[47] C. M. Guarino and V. M. H. Borden, Faculty service loads and gender: Are women taking care of the academic family?, Res. High. Educ. 58, 672 (2017).

[48] A. El-Alayli, A. A. Hansen-Brown, and M. Ceynar, Dancing backwards in high heels: Female professors experience more work demands and special favor requests, particularly from academically entitled students, Sex Roles 79, 136 (2018).

[49] K. Crenshaw, Mapping the Margins: Intersectionality, Identity Politics, and Violence against Women of Color, Stanford Law Rev. 43, 1241 (1991).

[50] M. Ong, Body projects of young women of color in physics: Intersections of gender, race, and science, Soc. Probl. 52, 593 (2005). 